\title{
(Sobre)vivendo nas Ruas: Habilidades Sociais e Valores de Crianças e Adolescentes
}

\author{
Tatiane Neme Campos 12 \\ Zilda Aparecida Pereira Del Prette \\ Almir Del Prette ${ }^{3}$ \\ Universidade Federal de São Carlos
}

\begin{abstract}
Resumo
As crianças e adolescentes em situação de rua apresentam valores e expectativas que podem ou não ser coerentes com suas estratégias de sobrevivência. Estas estratégias, por sua vez, ocorrem usualmente via interações sociais, possivelmente requerendo um elaborado repertório de habilidades interpessoais. O presente estudo investiga os valores, crenças e habilidades interpessoais junto a vinte e oito meninos nas ruas da cidade de São Carlos (SP). As informações foram coletadas por meio de conversas informais, entrevistas estruturadas e aplicação de um inventário de habilidades sociais. No caso deste último, efetuou-se um levantamento de freqüência dos comportamentos que então apresentados em tabelas. Os demais dados foram submetidos a uma análise de conteúdo. Os resultados mostraram que: a) a rua é utilizada como local de trabalho mais do que como moradia; b) as atividades realizadas pelas crianças requerem habilidades interpessoais, sendo mais freqüentes aquelas relacionadas à defesa de direitos, negociação e recusa; e, c) as crianças identificam valores e condutas socialmente valorizados, estabelecendo uma ética própria e apresentando desejos de ascensão social e de superação da situação em que se encontram. Discute-se a relação entre a realidade cotidiana dessa população, suas expectativas, valores e habilidades sociais para enfrentar essa realidade e os direitos previstos pelo Estatuto da Criança e do Adolescente.

Palavras-chave: Habilidades sociais; crianças de rua; cidadania; estratégias de sobrevivência.

Abstract

Surviving in the Streets: Social Skills and Values of Children and Adolescents

Children and adolescents living in the streets develop values and expectations that may or may not be coherent with thei survival strategies. These strategies happen through social interactions, possibly requiring an elaborated repertoire of interpersonal skills. This paper investigated these aspects in a sample of twenty-eight boys living in the streets in an inner city of São Carlos (São Paulo - Brazil). Data were gathered by informal chats, structured interviews and the application of a social skills inventory which were subsequently (organized in both thematic categories of content and in frequency tables). The results showed that: a) the streets are used as place to work more than to live (as home); b) the activities performed by the children performed required interpersonal skills, being more frequent those related to rights defense, negotiation and refusal; c) the boys acknowledge socially accepted values and conducts, establishing their own ethics and presenting expectations of social ascension - mainly by school eduction - and of overcoming their living conditions. It is discussed the relations among these population's daily by school education - and of overcoming their living conditions. It is discussed the relations among these population's daily
reality, their expectations, values and social skills required for coping with these conditions and the rights listed on the Child and Adolescent Brazilian Statute are discussed.

Keywords: Social skills; street children; citizenship; survival strategies.
\end{abstract}

A questão das crianças de rua pode ser assinalada como um dos sintomas mais agudos da crise social no contexto brasileiro, associada à exclusão e ausência de cidadania. A

'Endereço para correspondência: Rua Thomás Nogueira Gaia, 188, Jardim América, 14020-290, Ribeirão Preto, SP. Fone: (16) 6234770. E-mail: mmcampos@forp.usp.br.

Este trabalho é uma versão modificada da monografia de conclusão de curso da primeira autora, orientada pelos dois outros autores. Versões preliminares dos resultados foram apresentadas pela primeira autora no II Congreso Iberoamericano de Psicologia (Madrid, 1998) e na XXVII Reunião Anual da Sociedade Brasileira de Psicologia (Ribeirão Preto, 1998).

Os autores agradecem a participacão de Clayton dos Reis Marques, aluno do Curso de Graduação em Psicologia, na coleta de dados da primeira etapa deste trabalho. existência e o aumento dessa população demonstra, dramaticamente, que as garantias prometidas pela constituição não saíram do papel e que o direito de se viver decentemente ainda é proibitivo para muita gente (Dimenstein, 1995).

O conceito de crianças e adolescentes de rua tem sido objeto de discussão entre os pesquisadores da área. Alguns autores propõem a diferenciação conceitual entre crianças de rua e crianças na rua (Bandeira, Koller, Hutz \& Forster, 1994; Raffaelli, 1996) para evitar problemas metodológicos. O primeiro grupo (crianças de rua) seria formado por meninos e meninas, bem como adolescentes, que não possuem vínculo familiar, isto é, 
que abandonaram ou foram abandonados pela família e para as quais as ruas representam local de moradia, trabalho, lazer e relações afetivas. Alves e colaboradores (1998) caracterizam os componente deste primeiro grupo pela aparência de abandono, os aspectos de descuido e de falta de higiene, o vagar pelas ruas sozinhos ou em grupo, desacompanhados de um adulto responsável. O segundo grupo (crianças na rua) é constituído por aqueles que ficam grande parte do dia nas ruas, trabalhando, pedindo esmolas e brincando, utilizando os recursos obtidos para a sobrevivência própria e da família. Martins (1996a, 1996b) discute os vários critérios definidores para o uso do conceito de crianças na rua, tanto os propostos por instituições como a UNICEF, como por diversos pesquisadores. Sua posição é a de que os estudos tipológicos devem considerar, ainda, a família e a sociedade em que a criança está inserida. Neste segundo grupo, as crianças voltam para casa ao final do dia possuindo ainda um vínculo familiar. Segundo Rafaelli (1996, p.124), "a fronteira entre esses dois grupos é muito permeável e muitas crianças alternam-se entre eles, especialmente nos primeiros períodos de vivência nas ruas".

Em qualquer parte do mundo, o fenômeno de busca das ruas (100 milhões de pessoas, conforme a UNICEF) está relacionado com a pobreza, estimando-se que 75\% dessa população seja constituída por crianças adolescentes. Embora as estimativas e as metodologias utilizadas para a verificação sejam contraditórias (Rosemberg, 1996) o fato, em si, possui uma dimensão política inquestionável. Koller e Hutz (1996) preferem a terminologia "em situação de rua", para abranger os dois grupos, operacionalmente identificados com base no uso da rua, aparência (vestimenta e higiene) e atividade (trabalhar, perambular, esmolar e brincar). Nas cidades brasileiras, é freqüente a passagem episódica da criança e, principalmente, do adolescente, pelas ruas, com atividades e aparência acima descritas, sem que possam ser caracterizadas como vivendo na rua

A adaptabilidade do ser humano na luta cotidiana pela sobrevivência depende, entre outros aspectos, do uso e da adequação de estratégias às demandas impostas pela diferentes situações vivenciadas. $\mathrm{Na}$ análise de SwartKruger e Donald (1996), a flexibilidade e habilidade das crianças na/da rua para sobreviver resultam da necessidade de adaptar-se a condições adversas (sem o poder, nem os recursos físicos e psicológicos para tal) o que pode levar a estratégias "oportunistas" (mentir e enganar) ou a respostas pouco adaptativas (intoxicar-se, fugir, adotar crenças pouco realísticas) prejudiciais ao seu desenvolvimento. $\mathrm{Na}$ verdade, os autores identificam uma contradição entre a vulnerabilidade delas e sua capacidade de enfrentar situações, com "custos para o desenvolvimento" (perda de oportunidade para educação, proteção e assistência dos adultos) que se refletiriam em alta taxa de instabilidade emocional, incluindo enurese, comportamentos regressivos, ansiedade e depressão.

Alguns estudos (Aptekar, 1996; Koller \& Hutz, 1996; Rafaelli, 1996) indicam que a visão negativa sobre essa população vem mudando ou sendo amenizada nos últimos anos. Aptekar (1996) identifica mudanças nos estereótipos negativos sobre essas crianças e adolescentes, antes vistos como delinqüentes, viciados ou perturbados mentalmente, embora ainda em risco nesses aspectos. Hutz e Koller (1997) chamam a atenção, por outro lado, para a lacuna de pesquisas existente na área de desenvolvimento com essa população, o que, sem dúvida, dificulta uma avaliação mais precisa de possíveis problemas e seqüelas nas crianças que vivem essa condição. Para Rafaelli (1996), a percepção destas como problema social vem sendo direcionada para uma maior preocupação com o impacto da situação de vida sobre o seu desenvolvimento enquanto sobreviventes que buscam um caminho possível e viável para chegar à idade adulta.

As estratégias de sobrevivência, segundo Haguette (1982), estão relacionadas com a complementação de renda e representam truques adaptativos realizados no âmbito familiar, nos grupos ou nas comunidades, visando a manutenção da família. Elas são adquiridas nas experiências cotidianas com as demandas e necessidades impostas pela realidade circundante, por meio dos vários processos de aprendizagem e de desenvolvimento envolvidos como a observação direta, a instrução e a conseqüência. Certamente, algumas das estratégias aprendidas em casa servem como base para novas aquisições, por exemplo, a negociação e a afirmação de direitos que ocorrem predominantemente nas interações sociais.

A importância da interação social na aprendizagem e no desenvolvimento vem sendo há muito reconhecida (ver Vygotsky, 1984), podendo-se afirmar que a qualidade das relações a que as crianças são expostas mapeiam as diferentes realidades por elas assimiladas e, simultaneamente, os tipos de indivíduos construídos por essa realidade, influenciando o processo e o conteúdo do desenvolvimento de suas características pessoais (modo de agir, pensar e sentir) e concepções de mundo (Del Prette \& Del Prette, 1995).

As estratégias de sobrevivência, portanto, não se restringem ao aspecto material da garantia de alimento e abrigo mas incluem também as "estratégias de sobrevivência psíquica”, que Menezes e Brasil (1998, p. 
340) identificam nas formas de relacionamento hierárquicas e entre iguais e no desenvolvimento dos significados e sentidos, bem como das normas de relações intra e entre grupos. A sobrevivência das crianças em situação de rua depende, criticamente, de interações sociais sendo a natureza, a qualidade e a efetividade destas determinada, entre outros fatores, pelo repertório interpessoal do indivíduo e, ao mesmo tempo determinante do desenvolvimento desse repertório.

Pode-se afirmar que esses aspectos vêm sendo objeto de interesse na Psicologia, sob diferentes enfoques. O campo teórico-prático das Habilidades Sociais (termo que também designa um de seus conceitos-chave) é um deles. Trata-se de uma área que apresenta interfaces dentro da Psicologia (Desenvolvimento, Clínica, Social etc.) e com a Sociologia e a Antropologia e que vem se ampliando progressivamente em várias partes do mundo, embora, no Brasil, ainda seja relativamente incipiente (Del Prette \& Del Prette, 1996; 1999).

São muitas as definições de habilidades sociais encontradas na literatura e elas variam de acordo com os modelos teóricos adotados (Caballo, 1993). Não é objeto deste estudo discutir as questões pertinentes às definições veiculadas na área, podendo-se para isso remeter o leitor a vários outros autores (Hargie, Saunders \& Dickson, 1981/1994; Hidalgo \& Abarca, 1982; Trower, 1995). Para Del Prette e Del Prette (1999), as habilidades sociais (HS) podem ser definidas como "um constructo descritivo do conjunto de desempenhos apresentados pelo indivíduo diante das demandas de uma situação interpessoal" (p. 47). Tais desempenhos são caracterizados por componentes abertos, cognitivo-afetivos e fisiológicos que, quando adequadamente articulados entre si e ao contexto situacional e cultural, mostram-se serem funcionais para: a) a consecução dos objetos; b) a manutenção ou melhoria das relações com o interlocutor; c) a manutenção ou melhoria da auto-estima; d) a manutenção ou ampliação dos direitos humanos socialmente estabelecidos. Essa funcionalidade define a competência social do indivíduo. Muitas vezes, interações sociais insatisfatórias podem resultar tanto de déficits em habilidades sociais específicas como de dificuldade em articular produtivamente suas dimensões para obter as conseqüências acima referidas (Del Prette, Del Prette \& Barreto, 1999; Del Prette, Del Prette, Pontes \& Torres, 1998).

Vários autores (Caballo, 1993; Del Prette \& Del Prette, 1996, 1999; Feldman, 1992) destacam a necessidade de situar as habilidades sociais em um marco cultural determinado, pois os padrões de comunicação variam muito entre as culturas, bem como dentro da mesma Psicologia: Reflexão e Crítica, 2000, 13(3), pp.517-527 cultura, de acordo com a idade, sexo, classe social e educação. Assim, a análise das habilidades sociaisjuntamente com os aspectos cognitivos e afetivos a elas inerentes - das crianças e adolescentes em situação de rua, além de ampliar o conhecimento sobre o funcionamento psicológico destas, pode trazer elementos para a compreensão da dimensão cultural desse repertório.

A maior parte das pesquisas sobre as crianças e adolescentes $\mathrm{da} / \mathrm{na}$ rua têm focalizado as condições objetivas e de saúde dessa população mais do que o seu funcionamento e ajustamento psicológico (conforme Rafaelli, 1996), verificando-se, também, certa escassez de análise de procedimentos que envolvam a abordagem dessa clientela (Rosemberg, 1996). Em parte, isso pode estar ocorrendo em função da dificuldade de coleta de dados (Aptekar, 1996), mas também, possivelmente, em função da preocupação com o dimensionamento e caracterização geral dessa população como etapa prévia de outros estudos. De todo modo, a literatura psicológica no país não tem registrado estudos tomando as habilidades sociais como temática junto a essa população, provavelmente porque o interesse por essa área ainda é recente entre nós.

Com base nas considerações acima, e na predominância de meninos, mais do que meninas em situação de rua (cf. Maciel, Brito \& Camino, 1997), o objetivo deste trabalho foi o de descrever e analisar aspectos da competência social (habilidades, concepções e valores) presentes nas estratégias de sobrevivência utilizadas por meninos encontrados nas ruas de uma cidade, de aproximadamente 200 mil habitantes, do interior de São Paulo.

Método

\section{Participantes}

A amostra constituiu-se de 28 meninos que representavam, na época da coleta de dados, $44,5 \%$ das crianças e adolescentes que viviam pelas ruas, segundo o Conselho Tutelar da cidade de São Carlos (SP). A maioria dos participantes da pesquisa tinha idade entre 13 e 17 anos, com apenas um de 18 anos (S11). Os três mais jovens, com idade inferior a dez anos (S6, S7 e S8), freqüentavam a escola. Três respondentes (S9, S17 e S28) possuíam até a sexta série do Ensino Fundamental e ainda estudavam na época da coleta de dados; já os de menor nível de escolaridade haviam interrompido seus estudos. Os participantes, divididos em três subgrupos, conforme os instrumentos de coleta de dados utilizados, são apresentados na Tabela 1 
520 Tatiane Neme Campos, Zilda Aparecida Pereira Del Prette \& Almir Del Prette

Tabela 1. Distribuição dos Meninos em Subgrupos conforme os Instrumentos Utilizados na Coleta de Dados

\begin{tabular}{clc}
\hline Grupos & Participantes & Instrumento \\
\hline G1 & S1,S2,S3,S4,S5,S6,S7,S8,S9 e S10 & Conversas informais \\
G2 & S11, S12, S13, S14, S15 e S16 & Entrevista semi-estruturada \\
G3 & S15, S16, S17, S18, S19, S20, S21, S22, S23, S24, & Inventário de Avaliação \\
& S25, S26, S27 e S28 & \\
\hline
\end{tabular}

\section{Instrumentos}

Roteiro de Entrevista. Abordava dados pessoais (idade, escolaridade, mudanças de escola e motivos), forma de obtenção de recursos para sobrevivência (ajuda de familiares, trabalhos esporádicos, esmolas, furtos etc.), uso do dinheiro e da rua, qualidade das relações com a família, amigos e outros, rotina diária, desejos e aspirações.

Inventário de Habilidades, Crenças e Sentimentos (Anexo A). Adaptado de Del Prette, Del Prette e Barreto (1998), contendo 43 itens, dos quais: 15 descreviam situações interpessoais e uma reação indicadora de habilidade socia (cuja freqüência podia ser avaliada por meio de uma escala tipo Likert, de cinco pontos); 17 itens avaliavam o grau de competência na emissão dessas reações (também avaliada em uma escala de cinco pontos); e 11 apresentavam afirmações sobre crenças e sentimentos sobre direitos (para indicação de concordância ou discordância). Para conferir um caráter menos formal e mais concreto à avaliação, foi confeccionada uma régua especial com a ilustração dos níveis da escala e um indicador móvel manipulável pelo participante no momento de responder cada item. Em quatro itens do inventário, a redação utilizava um fraseado negativo ( 7 , 20, 28 e 32) cujos valores foram posteriormente invertidos para o cômputo dos escores dos respondentes.

\section{Procedimentos}

Coleta de Dados. Em uma etapa inicial, visitou-se as instituições de atendimento a crianças e adolescentes da cidade para familiarização com a situação dessa população. $\mathrm{Na}$ etapa seguinte procedeu-se à coleta de dados nas ruas centrais da cidade, primeiramente em conversas informais (registradas logo em seguida em um caderno) e, depois, em entrevistas gravadas e com aplicação do inventário. No caso do inventário, o entrevistador lia as questões e anotava as respostas, pedindo à criança que indicasse a freqüência e grau de dificuldade das reações lidas manipulando o indicador móvel e que expressasse verbalmente sua concordância ou discordância ao conteúdo dos demais itens.
No contato inicial com cada respondente, foi explicado que se tratava de um estudo da pesquisadora para obter maior conhecimento sobre as crianças que estavam nas ruas, solicitando-se o seu consentimento e garantindo-se o seu anonimato.

Análise dos Dados. As informações coletadas através de conversas informais e entrevistas foram examinadas, buscando-se identificar as classes de conteúdo referentes à experiência nas ruas e às estratégias de sobrevivência utilizadas. As informações colhidas com o inventário foram organizadas em tabelas de freqüência e dificuldade das reações indicadoras de habilidades sociais e das concordâncias com os conteúdos dos itens referentes a crenças, direitos e expectativas. Foi possível obter, em relação aos itens do inventário, valores médios por item e escores por sujeito.

\section{Resultados e Discussão}

\section{Dados de Conversas Informais e Entrevistas}

A análise do conteúdo das entrevistas e questionários sobre a experiência nas ruas e as estratégias de sobrevivência permitiu identificar três conjuntos de informações: a) uso do espaço físico das ruas; b) atividades; e c) a convivência com o uso de drogas. Os demais itens da entrevista de certo modo foram incluídos nesses três conjuntos, examinados a seguir.

\section{Uso do Espaço Físico das Ruas}

Nessa classe foram reunidas as informações referentes à relação rua-família e à questão territorial do uso do espaço das ruas. Todos os participantes relataram estar morando com a família no momento da coleta de dados, com exceção de S14 e S15 que moravam em uma pensão (mas não nas ruas). Ao término da coleta de dados, S24 relatou que ia sair de casa e morar na casa de um amigo. S16 relatou já ter morado um ano na rua com um grupo de amigos, que incluía o irmão (S24), mas no momento estava morando com a mãe. Pode-se afirmar, portanto, que esses meninos estão nas ruas principalmente para 
conseguir dinheiro, isto é, para trabalhar e sobreviver, como já identificado em outras pesquisas (Martins, 1996a; Rafaelli, 1996)

Quanto à utilização das ruas, S16 relatou que essa prática está sujeita a três critérios: a) o de chegar em primeiro lugar; b) o de obter permissão através de pedido; c) o de "comprar" o uso da rua. Ele relatou também que teve que "comprar o ponto" da rua na qual trabalhava vigiando carro, pagando com dinheiro (e não em espécie). Já S15 constituiu exceção, escapando desses critérios ao herdar o ponto com a morte do irmão que o ocupava. Possivelmente, o caso de morte do menino foi considerado uma justificativa razoável para a quebra das normas vigentes na concessão do ponto a seu irmão

Atividades

As ocupações, relatadas pelos participantes do G2 (entrevistas) para obter recursos financeiros foram agrupadas na Tabela 2 . relacionamentos interpessoais contínuos, em geral com estranhos, que demandam habilidade para abordar pessoas, manter e encerrar conversação, negociar, e até mesmo apresentar polidez, refletindo a importância da competência social destas crianças e adolescentes.

\section{Convivencia com o Uso de Drogas}

O relato de uso de drogas, obtido através de questões da entrevista, foi abordado como algo "natural" e corriqueiro pelos meninos. Apenas três deles (S11, S16 e S25) relataram usar ou já terem usado drogas por um tempo razoavelmente contínuo (durante dois meses), citando a maconha e o crack, embora tenham feito referência também à cola de sapateiro, colírio e cocaína. Esses dados não permitem classificar as crianças segundo a tipologia da OMS (Noto, Nappo, Galduroz, Mattei \& Carlini, 1997), que considera como usuário leve, aquele que usou droga numa freqüência menor do que semanal, de uma a três vezes no último mês; moderado, o que

Tabela 2. Tipos de Trabalhos Realizados pelos Participantes do G2

\begin{tabular}{ll}
\hline Trabalhos & Participantes \\
\hline vigiar carros & $\mathrm{S} 11, \mathrm{~S} 12, \mathrm{~S} 13, \mathrm{~S} 14, \mathrm{~S} 15, \mathrm{~S} 16$ \\
pedir esmolas & $\mathrm{S} 11, \mathrm{~S} 13$ \\
vender sorvetes nas ruas & $\mathrm{S} 11, \mathrm{~S} 15$ \\
office-boy em banco & $\mathrm{S} 15, \mathrm{~S} 16$ \\
servente de pedreiro & $\mathrm{S} 14, \mathrm{~S} 15$ \\
bater estaca & $\mathrm{S} 15, \mathrm{~S} 16$ \\
aquisição/venda de sucata, papelão & $\mathrm{S} 11, \mathrm{~S} 14$ \\
jardineiro & $\mathrm{S} 11, \mathrm{~S} 13$ \\
depósito de alumínio & $\mathrm{S} 14$ \\
sorveteria do Educandário & $\mathrm{S} 15$ \\
funilaria & $\mathrm{S} 14$ \\
telefonista & $\mathrm{S} 16$
\end{tabular}

Pela Tabela 2, percebe-se que os participantes trabalham em atividades como vigiar carro, vender sorvetes, serviços diversos de office-boy, aquisição e venda de sucatas e pedir esmolas, um conjunto semelhante ao encontrado em outros estudos (Bonamigo, 1996; Rosemberg, 1990). Essas atividades aparentemente exigem pouca ou nenhuma qualificação formal, embora requeiram certas habilidades cognitivas de cálculo e de planejamento na utilização de dinheiro para uso próprio (diversão e compra de guloseimas, roupas e sapatos) e para ajudar à família. Além disso, tais atividades envolvem usou drogas numa freqüência de uma a quatro vezes por semana no último mês e diário ou pesado, o que usou droga numa freqüência diária de cinco ou mais vezes por semana no último mês. A cola e o colírio são os solventes de maior consumo em capitais como Recife, Porto Alegre, São Paulo e Brasília (Noto e colaboradores, 1997). Todos as crianças pesquisadas relataram nunca terem "tomado baque" (droga na veia).

Com relação ao período de iniciação às drogas, S16 relatou ter começado a usá-las quando tinha 12 para 13 anos porque "os moleques usavam, nós andava em bando, aí um 
dia eu experimentei". Ele relatou a interrupção do uso quando começou a ir a uma igreja evangélica e diz usar hoje só cigarro comum. Fez referência também ao fato de ainda ir à igreja uma vez por mês. Possivelmente, a questão do valor (idéia de pecado) parece estar na base do abandono da droga, fortalecendo o comportamento de recusa quando confrontado com a situação de uso Uma outra criança (S16) relatou ainda as sensações propiciadas pelas diferentes drogas: "quando você cheira cola, vocêpensa numa coisa e começa a cheirar, mesmo que seja impossivel, você vê a coisa na sua frente e você está ali dentro"; já com a maconha "todas as coisas que o nego faz é engracado; a cocaina não faz̨ia efeito nenhum”; e "o crack só dá vontade de fumar mais, mas só fazia mal, dava dor no estômago e suador”. As referências à cocaína fazem supor que se tratava de produto falsificado, tanto pelo relato de ausência de efeito, como pela possível dificuldade de obtenção, uma vez que seu principalmente porque não estava inserido em outro de não consumidores, como era o caso de S16, que freqüentava a igreja evangélica.

\section{Dados do Inventário}

A freqüência e grau de dificuldade de reações indicadoras de habilidades sociais em resposta aos itens do inventário foram organizadas na Tabela 3, a seguir.

Conforme a Tabela 3, os itens relatados como mais freqüentes estão associados à defesa de direitos, negociação e recusa, porém uma análise mais detalhada, ajuda a entender melhor o significado dessas habilidades no contexto das condições de vida dos meninos avaliados.

\section{Dizer Não (Itens 7, 21 e 28)}

Houve relato de alta freqüência de emissão dessa habilidade nas situações que envolviam participar de

Tabela 3. Valor Médio da Freqüência de Comportamentos Especificados em Cada Item (o valor zero corresponde à freqüência mínima e o quatro à freqüência máxima)

\begin{tabular}{clc}
\hline No. do Item & Conteúdo do item & Valor Médio \\
\hline 18 & Pedir mais dinheiro para freguês que deu pouco & 0,57 \\
30 & Convencer amigo que não está com vontade de consumir droga a fazê-lo & 0,79 \\
1 & Expressar felicidade para círculo de amigos & 1,79 \\
3 & Levar na esportiva gozações dos amigos & 1,93 \\
27 & Obter sucesso na negociação com o empregador & 2,21 \\
32 & Reagir de forma não agressiva às críticas & 2,29 \\
5 & Fazer perguntas necessárias para tirar dúvidas na escola & 2,29 \\
9 & Negociar com familiar o dinheiro que conseguiu nas ruas & 2,36 \\
13 & Sair em vantagem nos rolos com os amigos & 2,43 \\
23 & Argumentar com dono do estabelecimento, mostrando os seus direitos & 2,43 \\
20 & Reagir de forma não agressiva quando não é pago pelo seu trabalho & 2,64 \\
16 & Expressar opinião quando outra pessoa não concorda & 2,86 \\
25 & Negociar com o empregador & 2,86 \\
14 & Defesa dos direitos, mesmo que o outro fique chateado & 3,00 \\
10 & Ser bem sucedido na negociação de dinheiro com o familiar & 3,07 \\
7 & Rejeitar fazer rolo com os amigos quando não quer fazê-lo & 3,21 \\
31 & Aceitar recusa de amigo ao consumo de droga & 3,31 \\
21 & Negar convite de amigo para roubar quando não está com vontade & 3,64 \\
28 & Rejeitar convite para consumir droga quando não está com vontade & 3,79 \\
\hline
\end{tabular}

custo está além da disponibilidade de recursos financeiras dessa população.

A descrição de S25 sobre o seu consumo, de duas a três pedras de crack por dia, e dos efeitos, inclusive da perda de peso ("onze quilos em uma semana") foi acrescida da informação de que era muito difícil "dizer não" quando convidado por um amigo. A necessidade de aceitação pelo grupo certamente lhe dificultava a recusa, infrações (roubar e consumir drogas, por exemplo) e/ ou negociação. Pode-se supor, portanto, que esses itens aferiam também crenças e valores sobre ações jurídica e socialmente aceitáveis. Pode-se inferir, ainda, que os participantes valorizavam essa habilidade no enfrentamento de muitas situações em que ela era requerida. 
Aceitar o Não (Item 31)

O relato de alta freqüência de emissão dessa habilidade social estava também associado à recusa de participação em infrações e, portanto, a crenças e valores. Como os comportamentos tomados como representativos destas habilidades (recusa em consumir drogas) estavam dentro do contexto de vida destes meninos, mas restritos a alguns tipos de situações que eles vivenciavam, seria interessante que estudos posteriores investigassem essa habilidade em outras situações de vida deles, tais como na família e na escola.

Defender Direitos (Item 14) e Expressar Opinião (Item 16)

Verificou-se o relato de alta freqüência dessas habilidades bem como uma alta homogeneidade nas respostas, podendo-se supor que elas estejam bastante fortalecidas no repertório dessa amostra.

Negociação (9, 18, 20, 23 e 25) e Competência nesta Habilidade $(10,13,27$ e 30$)$

Em alguns itens, o grupo respondeu de maneira homogênea e em outros de forma heterogênea. Assim, negociar com a família apareceu com freqüência média para todos, com relato de competência na emissão desse comportamento. Já a avaliação da negociação com fregueses e empregadores foi mais diversificada. Os meninos relatam emitir comportamentos de negociação com os usuários de sua força de trabalho, mas com um certo grau de dificuldade, o que pode ir levar, muitas vezes, a não atingir o objetivo desejado (trabalho). Podese considerar essa habilidade como tendo grande importância no repertório dessa população, de modo que intervenções voltadas para promover o repertório de HS deveriam contemplar esse aspecto.

Expressar Sentimentos (Item 1), Fazer Perguntas (Item 5) e Lidar com Criticas (Itens 3 e 32)

Verificou-se pequena variabilidade nas respostas a esses itens, com as médias concentradas nos pontos de baixa e média freqüência, permitindo levantar a hipótese de déficits destas habilidades no repertório dessa amostra. No entanto, essa questão deve ser melhor analisada em pesquisas futuras, pois talvez hajam habilidades sociais de outra natureza ou classe mais significativas na subcultura dessa população. Essa questão é importante uma vez que, por exemplo, a habilidade de fazer perguntas na escola, considerando que a maioria não estuda, bem como a habilidade de expressar sentimentos positivos por pessoas que convivem com a violência das ruas, podem fazer pouco sentido, ou pelo menos, ser menos significativa do que outras habilidades interpessoais Psicologia: Reflexão e Crítica, 2000, 13(3), pp.517-527 necessárias neste contexto. Certamente novas adaptações do instrumento ainda se fazem necessárias.

Crenças, Direitos e Expectativas (Itens 34 a 43)

Os dados referentes a esses aspectos são analisados, a seguir, complementando-se, na medida do possível com informações obtidas nas entrevistas. Verificou-se que os meninos que estão nas ruas, em sua maioria na atividade de vigiar carro ou desenvolvendo outro tipo de trabalho, relatam valores e condutas considerados adequados pela sociedade. Por exemplo, rejeitam a negociação para obter mais dinheiro com o proprietário do veículo possivelmente porque supõem-na uma ação semelhante a pedir esmolas. Foi marcante, nesse grupo, a diferenciação feita entre vigiar carro (atividade mais digna) e pedir esmolas (menos digna). O pedir parece ser entendido como algo que ofende à dignidade, como relata S25: “ $E$ bem melhor [vigiar carro], você não estápedindo nada para ninguém, dinheiro, nada, só está pedindo para olhar o carro". Quanto à atividade de vigiar carros, eles a realizam devido às contingências (necessidade), mas fica evidente também, pela fala de algumas crianças, que preferem um trabalho socialmente mais valorizado, como verificado em outros estudos (Maciel, Brito \& Camino, 1997).

Quanto às expectativas, verificou-se que os meninos manifestaram desejo de ascensão social, atribuindo à escola um papel de intermediária nesse processo. No entanto, mesmo acreditando que a escola favoreça a obtenção de um emprego e a realização de seus sonhos, muitos não se dedicam ao estudo, faltam às aulas ou evadem. Essas crianças e adolescentes fazem parte do contingente que sofre o fracasso do atual sistema educacional, ao deixar de fora, justamente, uma parcela com carências diversificadas, que incluem a aprendizagem acadêmica, mas, também outras, ligadas à cidadania e à defesa de direitos.

Estes dados sobre expectativas são coerentes com os de outros estudos (Swart-Kruger \& Donald, 1996; Tyler \& Tyler, 1996), onde se verificou que os desejos das crianças em situação de rua refletem valores e crenças pró-sociais com aspirações a relacionamentos positivos e a oportunidades educacionais e sociais próprias de uma sociedade mais justa, além de apresentarem um senso moral relativamente equivalente ao do restante sociedade.

\section{Conclusões}

Os resultados desse estudo justificam a preocupação explicitada em vários estudos (por exemplo, Hutz \& Koller, 1997; Bandeira, Koller, Hutz \& Forster, 1996) com as condições diferenciadas de desenvolvimento 
pessoal e interpessoal das crianças e adolescentes em situação de rua. Essas condições certamente interferem em suas possibilidades de ascensão social e de superação da situação em que se encontram (Swart-Kruger \& Donald, 1996), apesar de muitos estudos (Aptekar, 1996; Hutz \& Koller, 1997) as caracterizarem como resilientes no desenvolvimento de vários aspectos (pró-social capacidade de resolver problemas, relações de amizade) assemelhando-se às crianças que não enfrentam essa adversidades.

Ao lado (e provavelmente em função) dos perigos e riscos a que estão sujeitas as crianças em situação de rua, os dados sugerem que essa população desenvolve um conjunto de habilidades interpessoais. Tal repertório de habilidades sociais parece contribuir para a eficácia, pelo menos a curto prazo, das estratégias de sobrevivência que utilizam, porém também existem déficits em outras habilidades, igualmente importantes, para um desenvolvimento global harmonioso. Assim, defender direitos, negociar interesses, recusar e aceitar recusas e pedidos parecem situar-se entre as habilidades mais freqüentes que possuem. Paralelamente, parecem ser mais escassas as oportunidades de desenvolver habilidades de expressar sentimentos positivos, fazer perguntas, lidar com críticas e "chacotas" e controlar a agressividade.

Pode-se afirmar que se trata de crianças e adolescentes aos quais as oportunidades de uma vida "normal" e de realização pessoal estão sendo negadas pelo processo de exclusão que caracteriza a atual conjuntura social brasileira. A solução desse problema exige intervenção sobre seus múltiplos determinantes, desde mudanças na política econômica (de acordo com a análise de Maciel, Brito \& Camino, 1997) à implementação de projetos sociais específicos de atendimento, como as propostas de profissionalização dessa clientela (Bandeira, Koller, Hutz \& Forster, 1996) e de sua reintegração à educação formal (Castro, Moura \& Ribeiro, 1999; Rosemberg, 1996).

Nessa perspectiva, verificou-se que a população pesquisada revelou os valores da sociedade em geral sobre educação escolar e trabalho, com consciência de sua importância como recursos para superar as condições em que vivem, o que foi identificado igualmente em outros estudos (Bonamigo, 1996; Tyler \& Tyler, 1996) Trata-se, no caso da Educação, de um direito previsto no Estatuto da Criança e do Adolescente (ECA, Artigo 53) que deveria ser garantido:

"A criança e o adolescente têm direito à educação, visando ao pleno desenvolvimento de sua pessoa, preparo para o exercício da cidadania e qualificação para o trabalho, assegurando-se-lhes igualdade de condições para o acesso permanência na escola [...] e direito de ser respeitado pelos seus educadores..." (Cury, Silva \& Mendes, 1992, pp. 166167)

Além das dificuldades impostas pela necessidade mais urgente de obter recursos para a sobrevivência, a garantia desse direito esbarra com as poderosas restrições inerentes ao sistema escolar, como a insuficiência de escolas, a entrada tardia, as taxas elevadas de reprovação e a intensa evasão (Cunha, 1980) aliadas à ineficiência de um processo educativo que ignora a realidade das crianças e adolescentes em situação de rua. Como argumentam Bandeira, Koller, Hutz e Forster (1994), elas não são escolarizadas também porque o discurso da escola está muito distanciado de sua realidade. As cartilhas têm propostas ingênuas para o seu amadurecimento, as professoras falam de valores, como bem e mal, honestidade e desonestidade, que são relativos e circunstanciais para essa clientela e a escola faz exigências de comportamento (hábitos de higiene, postura e obediência) bastante diferentes daqueles construídos pela sua cultura de grupo psicossocial (Bandeira e colaboradores, 1994).

Somando-se à preocupação com o impacto das condições de vida sobre o desenvolvimento das crianças e adolescentes em situação de rua (Rafaelli, 1996), o presente estudo chama a atenção para um aspecto desse desenvolvimento, o interpessoal, que articula cognições, valores e habilidades, permitindo estabelecer relações entre tais processos psicológicos e a cultura construída por essas crianças em seus grupos. As dificuldades interpessoais identificadas, e também as habilidades aparentemente presentes no repertório desses meninos, apontam para a necessidade de se repensar a função social da educação escolar junto a essa clientela. Além disso, dever-se-á reforçar alternativas à educação formal (como aquelas propostas pelos educadores de rua) que, dentro da filosofia de garantir os deveres e direitos prescritos no Estatuto da Criança e do Adolescente, contemplem também o desenvolvimento social e emocional destes cidadãos.

\section{Referências}

Alves, P. B., Prade L.T., Reppold, C. T., Santos, C. L., Silva, A. S., Silva, M. R. \& Koller, S. (1998). Crianças em situação de rua: Subsídios para pesquisa e intervenção [Resumo]. Em Sociedade Brasileira de Psicologia do Desenvolvimento (Org.), Resumos de Comunicacōos Cientificicas, II Congresso da Sociedade Brasileira de Psicologia do Desenvolvimento (p. 81). Gramado: SBPD.

Aptekar, L. (1996). Crianças de rua nos países em desenvolvimento: Uma revisão de suas condições. Psicologia: Reflexão e Crítica, 9, 153-184.

Bandeira, D., Koller, S. H., Hutz, C. \& Forster, L. (1994). O cotidiano dos meninos de rua de Porto Alegre. Em Associação Brasileira de Psicologia Escolar e Educacional (Org.), Anais, XVII Internacional School Psycbology Coloquium (Tomo II, pp.133-134.). Campinas: ABRAPEE. 
Bandeira, D. R., Koller, S. H., Hutz, C. S. \& Forster, L. ( 1996). Desenvolvimento psicossocial e profissionalização: Uma experiência con adolescentes de risco. Psicologia: Reflexão e Crítica, 9, 185-208.

Bonamigo, L. R. (1996). O trabalho e a construção de identidade: Um estudo sobre meninos trabalhadores na rua. Psicologia: Reflexão e Crítica, 9, 129-152.

Caballo, V. E. (1993). Manual de evaluación y entrenamiento de las habilidades sociales. Madrid: Siglo XXI.

Castro, C. R., Moura, M. L. S \& Ribeiro A. (1999). Oficina de informática com meninos e meninas de rua: Relato de um experiência. Psicologia: Reflexão e Crítica, 12, 241-258.

Cunha, L. A. (1980). Educaáão e desenvolvimento social no Brasil. Rio de Janeiro, Francisco Alves.

Cury, M., Silva, A. F. A. \& Mendez, E. G. (Orgs.). (1992). Estatuto da criansa $e$ do adolescente comentado. São Paulo: Malheiros

Del Prette, A., Del Prette, Z. A. P. \& Barreto, M. C. M. (1999). Habilidades sociales en la formación del psicólogo: Análisis de un programa de intervención. Psicologia Conductual, 7, 27-47.

Del Prette, A., Del Prette, Z. A. P., Pontes, A. C. \& Torres, A. C. (1998). Efeitos de uma intervenção sobre a topografia das habilidades sociais de professores. Psicologia Escolar e Educacional, 2, 11-22.

Del Prette, Z. A. P. \& Del Prette, A. (1995). Notas sobre pensamento e linguagem em Skinner e Vygotsky. Psicologia: Reflexão e Crítica, 8, 147-164.

Del Prette, Z. A. P. \& Del Prette, A. (1996). Habilidades sociais: Uma área em desenvolvimento. Psicologia: Reflexão e Crítica, 9, 233-255.

Del Prette, Z. A. P. \& Del Prette, A. (1999). Psicologia das habilidades sociais: Terapia e educasãa. Rio de Janeiro: Vozes.
C.

Del Prette, Z. A. P., Del Prette, A. \& Barreto, M. C. M. (1998). Análise de um Inventário de Habilidades Sociais em uma amostra de universitários. Psicologia: Teoria e Pesquisa, 14, 219-228.

Dimenstein, G. (1995). O cidadão de papel. São Paulo: Ática.

Feldman, R. S. (1992). Applications of nonverbal behavioral theories and research. Hillsdale, NJ: Lawrence Erlbaum.

Haguette, T. M. F. (1982). O mito das estratégias de sobrevivência: Um estudo sobre o trabalhador urbano e sua familia. Fortaleza: UFC

Hargie, O., Saunders, C. \& Dickson, D. (1994). Social skills in interpersonal communication $\left(3^{3}\right.$ ed.). London: New York: Routledge (Original publicado em 1981)

Hidalgo, C. H. \& Abarca, N. M. (1992). Comunicacion interpersonal - Programa de entrenamiento en habilidades sociales. Santiago do Chile: Editorial Universitaria.

Hutz, C. S. \& Koller, S. H. (1997). Questões sobre o desenvolvimento de crianças em situção de rua. Estudes de Psicologia, 2, 175-197.

Koller, S. H. \& Hutz, C. S. (1996). Meninos e meninas em situação de rua: Dinâmica, diversidade e definição. Em S. H. Koller (Org.), Aplicaçōes da psicologia na melhoria da qualidade de vida (pp.11-34). Porto Alegre: Associação Nacional de Pesquisa e Pós-Graduação em Psicologia.
Maciel, C., Brito, S. \& Camino, L. (1997). Caracterização dos meninos em situação de rua de João Pessoa. Psicologia: Reflexão e Crítica, 10, 315-334. Martins, R. A. (1996a). Censo de crianças e adolescentes em situação de rua em São José do Rio Preto. Psicologia: Reflexão e Crítica, 9, 101-122. Martins, R. A. (1996b). Crianças e adolescentes em situação de rua: Definições, evolução e políticas de atendimento. Em S. H. Koller (Org.), Aplicąôes da psicologia na melhoria da qualidade de vida (pp.35-44). Porto Alegre: Associação Nacional de Pesquisa e Pós-Graduação em Psicologia.

Menezes, D. M. A. \& Brasil, K. C. T. (1998). Dimensões psíquicas e sociais da criança e do adolescente em situação de rua. Psicologia: Reflexão e Crítica, 11, 327-344.

Noto, A. R. Nappo, S., Galduróz, J. C. F., Mattei, R. \& Carlini, E. A. (1997). IV Levantamento sobre o uso de drogas entre crianças e adolescentes em situação de rua de seis capitais brasileiras. São Paulo: CEBRID UNIFESP.

Rafaelli, M. (1996). Crianças e adolescentes de rua na América Latina: Artful Dodger ou Oliver Twist? Psicologia: Reflexão e Crítica, 9, 123-128.

Rosemberg, F. (1990). A concepção de família subjacente a programas para crianças e adolescentes em situação de rua. Em E. A. Carlini (Org.), Abuso de drogas entre meninos e meninas de rua do Brasil (pp. 87-90). São Paulo: Ave Maria.

Rosemberg, F. (1996). Estimativa sobre crianças e adolescentes em situação de rua: Procedimentos de uma pesquisa. Psicologia: Reflexão e Crítica, 9, 21-58.

Swart-Kruger, J. \& Donald, D. (1996). Crianças das ruas da África do Sul. Psicologia: Reflexão e Crítica, 9, 59-82

Trower, P. (1995). Adult social skills: State of the art and future directions. Em W. O'Donohue \& L. Krasner (Orgs.), Handbook of psychological skills. training: Clinical techniques and applications (pp. 54-80). New York: Allyn and Bacon.

Tyler, F. B. \& Tyler, S. L. (1996). Crianças de rua e dignidade humana. Psicologia: Reflexão e Crítica, 9, 83-100.

Vygotsky, L. S. (1984). A formacão social da mente: O desenvolvimento dos processo.s psicológicos superiores. São Paulo: Martins Fontes.

Sobre os Autores:

Tatiane Neme Campos é Psicóloga e, na ocasião da produção deste artigo, cursava o $5^{\circ}$ ano do Curso de Graduação em Psicologia, pela Universidade Federal de São Carlos.

Zilda Aparecida Pereira Del Prette é Psicóloga, Doutora pela Universidade de São Paulo, Docente e Orientadora dos Programas de Pós-Graduação em Educação Especial da UFSCar e de Psicologia da USP/Ribeirão Preto, Coordenadora do Laboratório de Interação Social (LIS). É bolsista de Produtividade em Pesquisa do CNPq.

Almir Del Prette é Psicólogo, Doutor pela Universidade de São Paulo, Professor aposentado pela UFSCAr, Docente dos Programas de Pós-Graduação em Educação Especial da UFSCar e de Psicologia da USP/Ribeirão Preto. É bolsista de Produtividade em Pesquisa do CNPq. 


\section{Anexo A}

\section{Inventário de Habilidades Sociais, Crenças e Sentimentos}

\section{Instruções}

Eu vou ler vários itens para você. Alguns apresentam uma ação, sentimento ou crença, que aparecem aqui destacados, veja, junto com a situação onde ocorrem. Em outros itens, eu vou perguntar se você sente dificuldade para reagir da forma aqui sugerida. Peço que você responda cada item falando sobre a freqüência ou a intensidade da sua reação, indicando, nesta escala a sua resposta. A escala tem um ponto zero, que corresponde ao nunca, o ponto um é quase nunca, o dois é algumas vezes, o três é quase sempre e o quatro é o sempre. Há ainda outros itens em que vou pedir que você me responda concordando ou discordando das afirmações que vou ler para você. Caso uma dessas situaçoes nunca lhe tenha acontecido, responda como se tivesse ocorrido, considerando seu possivel comportamento. Você entendeu? Se precisar eu lhe explico de novo.

\section{Itens}

1. Quando está se sentindo feliz, expressa (conta) isso para as pessoas do círculo de amizade (família, amigos $\quad \square 0 \square 1 \square 2 \square 3 \square 4$ da escola e da rua)?

2. Qual o grau de dificuldade que você tem para expressar isto?

$\square 0 \square 1 \square 2 \square 3 \square 4$

3. "Leva na esportiva" as gozações de colega da escola ou da rua a seu respeito?

$\square 0 \square 1 \square 2 \square 3 \square 4$

4. Qual o grau de dificuldade de se controlar?

$\square 0 \square 1 \square 2 \square 3 \square 4$

5. Na escola, quando não entende algo, faz as perguntas necessárias para seu entendimento?

$\square 0 \square 1 \square 2 \square 3 \square 4$

6. Qual o grau de dificuldade de fazer essas perguntas?

7. Quando algum colega quer "fazer rolo" [negociar] com você ( troca de pertences), mesmo não querendo, você acaba aceitando a troca?

8. Qual o grau de dificuldade de recusar a troca?

9. Considerando que seu pai/mãe/outro queira ficar com parte do dinheiro que você conseguiu na rua, e você também quer ficar com este, você negocia o que quer com eles?

10. Considerando as vezes que é necessário negociar com a mãe/pai, quantas vežes você obtém sucesso?

11. Qual o grau de dificuldade dessa negociação?

12. Qual o grau de dificuldade de "fazer rolo" com os amigos?

13. Das vezes nas quais você "faz rolo" com os colegas, quantas vežes você sai em vantagem?

$\square 0 \square 1 \square 2 \square 3 \square 4$

$\square 0 \square 1 \square 2 \square 3 \square 4$

14. Você defende os seus direitos, mesmo que o outro fique chateado?

15. Qual o grau de dificuldade dessa defesa?

16. Expressa suas opiniões para as pessoas com quem convive, mesmo que elas não concordem comestas?

17. Qual o grau de dificuldade dessa expressão?

18. Vocêpede mais dinheiro para um freguês que lhe deu pouco?

19. Qual o grau de dificuldade de fazer isto?

20. Quando alguma pessoa não quer lhe pagar pelo seu trabalho ("olhar" carro, engraxar sapato, outros), você costuma reagir de forma agressiva?

21. Quando algum colega convida-o para roubar algo que "está manha" [está fácil], se você não estiver afim [querendo], você nega?

$\square 0 \square 1 \square 2 \square 3 \square 4$

$\square 0 \square 1 \square 2 \square 3 \square 4$

$\square 0 \square 1 \square 2 \square 3 \square 4$

$\square 0 \square 1 \square 2 \square 3 \square 4$

$\square 0 \square 1 \square 2 \square 3 \square 4$

$\square 0 \square 1 \square 2 \square 3 \square 4$

$\square 0 \square 1 \square 2 \square 3 \square 4$

$\square 0 \square 1 \square 2 \square 3 \square 4$

$\square 0 \square 1 \square 2 \square 3 \square 4$

$\square 0 \square 1 \square 2 \square 3 \square 4$

$\square 0 \square 1 \square 2 \square 3 \square 4$

$\square 0 \square 1 \square 2 \square 3 \square 4$

2. Qual o grau de dificuldade em negar?

$\square 0 \square 1 \square 2 \square 3 \square 4$

$\square 0 \square 1 \square 2 \square 3 \square 4$

23. Quando algum dono de restaurante ou outro lugar no qual você guarda carro acha ruim por

você estar trabalhando em frente ao seu estabelecimento, você insiste com ele, mostrando seus direitos?

24. Qual o grau de dificuldade dessa argumentação?

25. Se estiver interessado em um emprego fora das ruas, você negocia com o empregador?

26. Qual o grau de dificuldade dessa negociação?

$\square 0 \square 1 \square 2 \square 3 \square 4$

$\square 0 \square 1 \square 2 \square 3 \square 4$

$\square 0 \square 1 \square 2 \square 3 \square 4$

27. Das vezes em que é necessário negociar com o empregador, quantas vezes você obtém sucesso (consegue o emprego).

28. Quando algum amigo lhe convida para consumir alguma droga (fumar maconha, crack, outros), mesmo não querendo, acaba aceitando o convite.

$\square 0 \square 1 \square 2 \square 3 \square 4$

$\square 0 \square 1 \square 2 \square 3 \square 4$ 
29. Qual o grau de dificuldade de recusar o convite?

$\square 0 \square 1 \square 2 \square 3 \square 4$

30. Quando você convida um amigo para fumar maconha ou crack, mesmo que ele não queira, ele acaba aceitando?

$\square 0 \square 1 \square 2 \square 3 \square 4$

31. Quando você convida um amigo para fumar maconha ou crack, caso ele não queira,_você aceita a recusa dele, sem ficar chateado?

32. Quando um de seus familiares ou colega de rua, por algum motivo, lhe critica, você costuma reagir de forma agressiva?

33. Acha que a mãe, pai ou outro tem todo o direito de ficar com todo o dinheiro que você ganhou?

34. Acha que tem o direito de ser tratado com respeito e dignidade?

35. Acredita que tem o direito de ser independente, ou seja, de fazer as coisas que você acha que deve sem interferência dos outros?

36. Acredita ter o direito de decidir o que fazer com o próprio corpo?

$\square 0 \square 1 \square 2 \square 3 \square 4$

$\square 0 \square 1 \square 2 \square 3 \square 4$

$\square \operatorname{sim} \square$ não

$\square$ sim $\square$ não

$\square \operatorname{sim} \square$ não

$\square \operatorname{sim} \square$ não

37. Acha que tem o direito de trabalhar na rua - olhando os carros, engraxando sapatos, outros?

38. Acha que tem o direito de pedir roupas, alimentos e dinheiro nas ruas e nas portas das casas?

39. Pensa que as pessoas tem o direito de recusar-lhe ajuda?

$\square \operatorname{sim} \square$ não

40. Pensa que tem pleno direito de fazer o que quiser com as coisas que lhe pertence, inclusive dinheiro?

41. Acredita que "olhar" carro é melhor que pedir?

42. Sente-se sozinho trabalhando nas ruas?

43. Nos conflitos com a polícia, acha que a mesma "não vira nada" [não tem maiores conseqüências?

$\square \operatorname{sim} \square$ não

$\square \operatorname{sim} \square$ não

$\square \operatorname{sim} \square$ não

$\square \operatorname{sim} \square$ não

$\square \operatorname{sim} \square$ não

$\square$ sim $\square$ não 